\title{
Head position and its effect on pulmonary function in tetraplegic patients
}

\author{
Cheryl Amodie-Storey ${ }^{1}$, Mark S Nash ${ }^{2,3}$, Pamela M Roussell ${ }^{2}$, Anne W Knox ${ }^{2}$ and Linda D Crane ${ }^{1,2}$ \\ ${ }^{1}$ Department of Physical Therapy, University of Miami/Jackson Memorial Rehabilitation Center, 1611 Northwest \\ 12th Avenue, Miami, FL 33136 USA; '2Division of Physical Therapy, Department of Orthopaedics \& Rehabilitation, \\ University of Miami School of Medicine, 5915 Ponce de Leon Blvd., 5th Floor, Coral Gables, FL 33146 USA; ${ }^{3}$ The \\ Miami Project to Cure Paralysis, University of Miami School of Medicine, 1600 Northwest 10th Avenue, R-48, \\ Miami, FL 33136, USA
}

To test the influence of head position on pulmonary function in tetraplegic individuals 15 subjects with chronic $\mathrm{C}_{4}-\mathrm{C}_{7}$ injuries participated in a one group pre-post test comparing the relationship between orthostatic position of the head $(\mathrm{OPH})$ and standard pulmonary function tests (PFTs). Twelve subjects with habitual forward head posture and three with non-forward head posture performed PFTs in (1) their habitual posture, and (2) an experimental posture imposed by placement of thoracic and/or lumbar rolls behind their back. Results showed that changing head posture did not alter mid-forced expiratory flow or forced inspiratory vital capacity, but significantly affected forced vital capacity $(t=2.83 ; P<0.05)$ and $12 \mathrm{~s}$ maximum voluntary ventilation $(t=2.07 ; P<0.05)$. In cases where pulmonary function was altered by head position, the resulting performance was best in the subject's habitual posture, although no differences in resting pulmonary tests were observed between subjects with and without forward head position. These data show that temporary postural alterations affecting $\mathrm{OPH}$, if not allowing sufficient time for muscular adaptation, adversely affect pulmonary function in tetraplegic patients.

Keywords: tetraplegia; pulmonary; ventilation; head position; pulmonary function tests

\section{Introduction}

Neuromuscular diseases and neurotrauma affecting muscles and posture of the neck and trunk are often associated with inefficient movement of the chest wall and diaphragm, and compromised pulmonary ventilation. Such respiratory dysfunction commonly occurs following cervical spinal cord injury, ${ }^{1-4}$ in which progressively greater degrees of pulmonary impairment are strongly associated with ascending levels of cord lesion. ${ }^{5,6}$ While survivors of complete tetraplegia below the third cervical vertebra retain the ability to use their diaphragm during inspiration, the primary expiratory muscles, including the abdominals, are often paralyzed. ${ }^{7}$ This accounts for previous reports in which survivors of spinal cord injury experience paradoxical movement of the chest wall during their breathing cycle, reduced total lung capacity (TLC), vital capacity (VC), forced vital capacity (FCC), and expiratory reserve volume (ERV), ${ }^{1,6,8} \cdot 10$ but increased residual volume $(\mathrm{RV}) .^{3-9,11,12-17}$

It is known that paralysis of the intercostals and abdominals in tetraplegic patients increases the burden of neck and shoulder muscles during breathing. $5,6,11,18$ Thus, several muscles or muscle groups, including the scalenes, sternocleidomastoids, and trapezius muscles,

Correspondence: MS Nash must share greater dual functions both of maintaining head posture and assisting in ventilation. For example, when stabilized at their sternoclavicular and first rib attachments, the sternocleidomastoid and scalenes flex the neck and assist its rotation, respectively. In this capacity they function as postural muscles that serve to properly align the head. ${ }^{19}$ Conversely, the scalenes assist in respiration via their attachment to the upper rib cage ${ }^{19,20}$ while the trapezius muscles are recruited during inspiration to stabilize the head and prevent excessive shortening of the sternocleidomastoids as they draw the sternum cranially. ${ }^{21}$ The platysma, myohyoids, and sternohyoids also depend on stabilization by the trapezius muscles during ventilation, ${ }^{21}$ as their simultaneous contraction pulls the sternum cranially, expands the upper rib cage, and inwardly displaces the lateral walls of the lower rib cage. ${ }^{21}$

Examination of individuals without neurological disability has shown that prolonged sitting is associated with forward head inclination caused by decreased lumbar lordosis. ${ }^{22}$ This forward head position and rounded shoulders shortens the cervical extensors, serratus anterior, pectoralis minor and upper trapezius muscles, and lengthens the cervical flexors, middle, and lower trapezius muscles. ${ }^{23}$ Habitual postural malalignment of these muscles, however slight, may lead to alterations in their 
length-tension properties, and decrease their ability to generate peak tension during either breathing or head stabilization. Whilst the respiratory function of those who are tetraplegic is reported to differ in the supine, sitting, and upright positions, ${ }^{6}$ the possibility that subtle changes in head position similarly alters pulmonary function has yet to be investigated. Thus, the purpose of this study was to (1) determine whether tetraplegic individuals display forward head posture as assessed by standard criteria, and (2) assess whether their pulmonary function is altered by experimental manipulation of head position.

\section{Methods}

\section{Subjects}

The subjects were fifteen volunteers (14 males and one female) aged 18 to 31 years with tetraplegias (Frankel Grades A-C) at the C4-C7 levels. They were screened by a personal interview and written questionnaire to exclude those having (a) duration of injury less than 3 months, (b) mechanical ventilatory support within 8 weeks of study testing, (c) artificial airway, (d) history of chronic obstructive pulmonary disease, (e) pneumonia within 2 weeks of testing, (f) asthma, (g) acute active communicable disease, and (h) surgical procedure performed within 4 weeks of testing. Subjects consented to participate in the study in accordance with the guidelines and approval of the Medical Sciences Subcommittee for the Protection of Human Subjects. Descriptive characteristics of the subjects are shown in Table 1.

Postural analysis

The orthostatic position of the head $(\mathrm{OPH})$ was

Table 1 Descriptive characteristics of the study subjects

\begin{tabular}{lcccc}
\hline Subject\# & $\begin{array}{c}\text { Age } \\
\text { (years) }\end{array}$ & Gender & $\begin{array}{c}\text { Level of } \\
\text { injury }\end{array}$ & $\begin{array}{c}\text { Injury } \\
\text { duration } \\
\text { (years) }\end{array}$ \\
\hline 1 & 30 & M & C5-6 & 13.0 \\
2 & 30 & M & C4 & 3.0 \\
3 & 18 & M & C4 -5 & 0.7 \\
4 & 28 & M & C5 & 6.1 \\
5 & 20 & M & C5-6 & 2.8 \\
6 & 29 & M & C5 & 4.2 \\
7 & 30 & M & C3 -4 & 1.3 \\
8 & 22 & M & C5 -6 & 2.8 \\
9 & 20 & M & C6 & 1.4 \\
10 & 19 & M & C6-C7 & 0.8 \\
11 & 27 & M & C6 & 8.2 \\
12 & 27 & F & C5 & 2.8 \\
13 & 31 & M & C5 -6 & 8.3 \\
14 & 25 & M & C4 -5 & 2.5 \\
15 & 28 & M & C5 -6 & 4.7 \\
Mean & 25.6 & & & 4.2 \\
SD & 4.4 & & & 3.3 \\
\hline
\end{tabular}

determined by the Rocabado technique in which the horizontal distance between the following sites is measured (1) a vertical tangent through the apex of the thoracic spine, and (2) the surface of the midcervical spine (Figure 1). ${ }^{24}$ This distance averages 6 centimeters $(\mathrm{cm})$ in persons without postural dysfunction, while those with abnormal posture display an OPH greater than $6 \mathrm{~cm}^{24}$ Thus, non-forward and forward head postures for this study were operationally defined as OPH less than, or greater than $6 \mathrm{~cm}$, respectively. Intra-rater reliability measured prior to this study established the following intra-class correlation coefficients: mid-cervical $=0.99$, thoracic apex $=0.99$.

Measurement of the OPH was performed with the back of the subject's wheelchair placed parallel to a wall and a posture grid positioned at their side. With subjects assuming their habitual posture, including the forearms placed on their wheelchair armrests, the distances from the apex of the thoracic spine to the wall and the mid-cervical spine to the wall were gauged with a tape measure. Three measurements were taken from each site, the average difference of which determined the $\mathrm{OPH}$.

\section{D1 $=$ Mean distance wall to thoracic apex D2 = Mean distance wall to mid-cervical spine $\mathrm{OPH}=\mathrm{D2}-\mathrm{D} 1$}

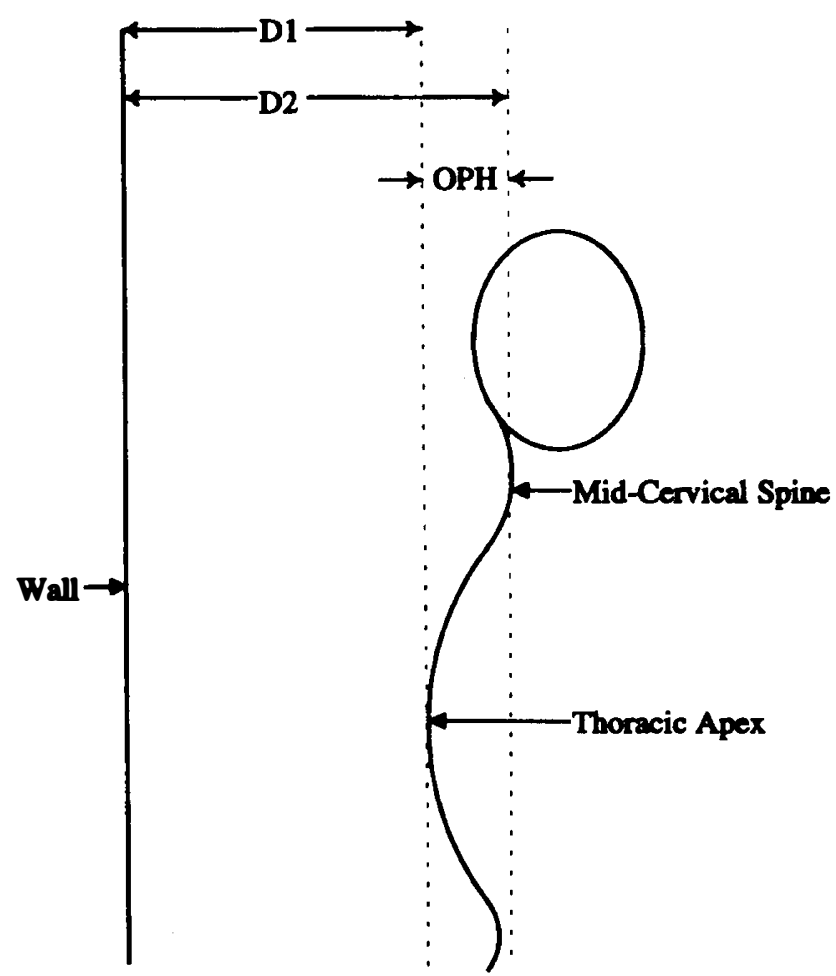

Figure 1 Schematic showing the Rocabado technique used for measuring the orthostatic position of the head (OPH) 


\section{Postural modifications}

Subjects performed pulmonary function tests (PFT) in their habitual posture and an experimentally-imposed posture. If the subject met the study criteria for forward head posture (ie $\mathrm{OPH}>6 \mathrm{~cm}$ ), the $\mathrm{OPH}$ was experimentally altered to $<6 \mathrm{~cm}$ by placing rolled cloth towels in the lumbar- to mid-thoracic spine regions. Conversely, in cases where the subject displayed habitual non-forward head posture (ie $\mathrm{OPH}<6 \mathrm{~cm}$ ), the position was altered to $>6 \mathrm{~cm}$ by placement of the towel rolls in the mid- to upperthoracic regions.

\section{Pulmonary function tests}

Pulmonary function tests (PFT) were performed on a Horizon System Pulmonary Function Analyzer (SensorMedics Corporation, Loma Linda, CA) interfaced with a computer microprocessor. The analyzer was standardized prior to each trial using a 5 liter calibration syringe. Standard pulmonary flow-volume loops were generated under both test conditions from which the following variables were derived (1) forced vital capacity (FVC), (2) forced mid-expiratory flow $\left(\mathrm{FEF}_{25}-75\right)$, and (3) forced inspiratory vital capacity (FIVC). Additionally, a standard $12 \mathrm{~s}$ maximum voluntary ventilation (MVV) challenge was performed in both the habitual and experimental head posture.

Subjects performed three PFT trials in which the order of testing for habitual and experimental postures was randomized. Two minutes of test separated each trial. Following a $10 \mathrm{~min}$ rest period, subjects underwent one MVV challenge and then rested for $10 \mathrm{~min}$ during which postural adjustments (placement or removal of towels) and postural analysis were performed. Three PFT trials and one MVV trial were then repeated. Verbal encouragement was given to subjects throughout the tests.

To minimize head movement, ensure sitting stability, and provide balance support during the PFT, an investigator stood behind the subject's wheelchair and provided light bilateral tactile support inferior to the mid-clavicular region. The subjects were videotaped from the lateral view using a posture grid to confirm that their position was unchanged during the PFT and assess whether untoward movement occurred during testing.

\section{Data analysis}

The study used a one group pre-post test design in which the best effort of three trials in the habitual and test postures for FVC, $\mathrm{FEF}_{25-75}, \mathrm{FIVC}$, and MVV, were analyzed. Differences in pulmonary performance were analyzed using paired Student $t$ tests, with the criterion for significance set at $P<0.05$. All data were analyzed using a Statistical Analytical System (SAS) software program (SAS Institute Inca Cary, NC).

\section{Results}

Table 2 shows the habitual head posture for the 15 subjects and their FVC and MVV tests in both habitual and experimentally-altered positions. Table 3 shows the FIVC and $\mathrm{FEF}_{25-75}$ pulmonary tests for the same habitual and altered head positions. Eighty percent $(\%)(12 / 15)$ of the subjects displayed habitual forward head posture of $8.8 \pm 1.6($ mean $\pm \mathrm{SD}) \mathrm{cm}$. One subject (\#1) with a profound habitual forward head position was not correctable to a non-forward position, as this adjustment caused him to lose his sitting balance. Thus, his experimentally-altered head position was defined as the greatest possible correction without imposing sitting instability $(6.5 \mathrm{~cm})$.

Table 2 Effect of habitual and experimentally-altered head position on forced vital capacity (FVC) and maximum ventilatory volume $\left(\mathrm{MV}_{12}\right)$ in subjects with forward and non-forward head posture

\begin{tabular}{|c|c|c|c|c|c|c|}
\hline \multirow[b]{2}{*}{ Subject\# } & \multicolumn{6}{|c|}{$\begin{array}{l}\text { Subjects with habitual forward head posture } \\
\text { Habitual } \\
\text { Altered }\end{array}$} \\
\hline & $\begin{array}{l}O P H \\
(\mathrm{~cm})\end{array}$ & $\begin{array}{l}F V C \\
(L)\end{array}$ & $\begin{array}{l}M V V \\
(L / \text { min })\end{array}$ & $\begin{array}{l}O P H \\
(\mathrm{~cm})\end{array}$ & $\begin{array}{c}F V C \\
(L) \\
\end{array}$ & $\begin{array}{l}M V V \\
(L / \text { min })\end{array}$ \\
\hline 1 & 11.35 & 4.02 & 152 & $6.50^{1}$ & 3.23 & 112 \\
\hline 2 & 7.35 & 1.29 & 44 & 5.35 & 1.62 & 67 \\
\hline 4 & 8.21 & 4.24 & 162 & 3.54 & 3.96 & 104 \\
\hline 5 & 11.63 & 2.18 & 84 & 4.97 & 1.89 & 61 \\
\hline 6 & 6.14 & 2.18 & 64 & 3.97 & 2.03 & 39 \\
\hline 7 & 8.26 & 2.63 & 68 & 3.71 & 1.96 & 56 \\
\hline 8 & 10.41 & 2.97 & 132 & 4.39 & 2.83 & 128 \\
\hline 9 & 8.78 & 2.45 & 141 & 3.92 & 2.28 & 125 \\
\hline 12 & 7.34 & 1.78 & 45 & 5.09 & 1.84 & 70 \\
\hline 13 & 10.11 & 2.40 & 124 & 5.40 & 2.42 & 110 \\
\hline 14 & 7.46 & 2.21 & 86 & 5.30 & 2.31 & 85 \\
\hline 15 & 8.88 & 2.29 & 62 & 5.28 & 1.80 & 59 \\
\hline Mean & 8.8 & $2.62^{2}$ & $97.0^{2}$ & 4.8 & 2.4 & 84.7 \\
\hline SD & 1.6 & 0.8 & 40.9 & 0.8 & 0.7 & 28.8 \\
\hline 3 & 5.25 & 2.73 & 91 & 6.99 & 2.40 & 94 \\
\hline 10 & 2.27 & 2.25 & 87 & 6.50 & 2.23 & 72 \\
\hline 11 & 4.88 & 2.63 & 102 & 12.22 & 2.18 & 79 \\
\hline Mea & 4.1 & 2.5 & 93.3 & 8.4 & 2.3 & 81.7 \\
\hline SD & 1.3 & 0.2 & 6.3 & 2.5 & 0.1 & 9.2 \\
\hline
\end{tabular}

Correction greater than this amount caused the subject to lose his balance. ${ }^{2}$ Differing significantly from the experimentally-altered condition $(P<0.05)$

Table 3 Effect of habitual and experimentally-altered head poistion on forced inspiratory vital capacity e(FIVC) and mid-expiratory forced expiratory force $\left(\mathrm{FEF}_{25-75}\right)$ in subjects with forward and non-forward head posture. OPH measurements are identical to those shown in Table 2

\begin{tabular}{lcccc}
\hline & \multicolumn{2}{c}{ Habitual } & \multicolumn{2}{c}{ Altered } \\
& FIVC & FEF $25-75$ & FIVC & FEF $25-75$ \\
$-\ldots$ & $(L)$ & $($ L $/$ min $)$ & $(L)$ & $(L / m i n)$ \\
Mean & 2.5 & 3.4 & 2.3 & 3.2 \\
SD & 0.8 & 1.2 & 0.6 & 1.1 \\
\hline
\end{tabular}


A significant effect of head posture on pulmonary function was observed for FVC $(t=2.83 ; P<.05)$ and MVV $(t=2.07 ; P<0.05)$ with pulmonary volumes for these variables averaging $8.5 \%$ and $14.5 \%$ greater in the habitual than altered position, respectively. In most cases, the larger lung volumes and flow rates were observed when testing the subjects' habitual position, regardless of forward head or not. For example, only four subjects had greater FVC in their altered than native position (\# 2,12,13, and 14), with three of these cases (\#12, 13, and 14) representing clinically-nominal differences. Similarly, only three subjects had a higher MVV in the altered position (\#s 2, 3 and 12), with one case (\#3) representing only a $3.2 \%$ increase. Averages for FIVC and $\mathrm{FEF}_{25-75}$ were lower in the non-habitual posture, but this difference was not significant.

\section{Discussion}

The pulmonary responses of subjects in their habitual sitting position are consistent with previous reports of pulmonary limitation after cervical spinal cord injury. ${ }^{1-14}$ These studies have observed restrictions of functional capacity and forced expiratory volume in one second (FEV-1) of those with tetraplegia in the upright, sitting, and supine positions when compared to nondisabled control subjects. ${ }^{11,14}$ These differences are attributed to respiratory muscle paralysis below the level of spinal cord injury which results in excessive excursion of the abdominal wall and viscera during inspiration. ${ }^{16,25}$ This excessive motion is accompanied by paradoxical movement of the chest wall and inward movement of the rib cage during inspiration as the diaphragm descends toward the abdomen. ${ }^{12,13,16,21,25,26}$

The results of this study reveal two novel findings. First, that a high percentage of individuals with tetraplegia display forward head posture; and second, that deviation from habitual posture - in most cases whether forward head or not - compromises pulmonary function. In biomechanical studies, this type of forward head position has most often been associated with 'postural' headache in which the dorsal neck muscles function as antagonists to gravity. ${ }^{27}$ Recent electromyographic (EMG) study has shown that a deficiency of neck muscle performance accompanies repositioning of the head into non-neutral positions. ${ }^{28,29}$ Acute changes in muscle length alone were believed to be the cause for abnormal integrated EMG/muscle moment relationships observed in these non-neutral postures. ${ }^{30}$ That this position-dependent muscle insufficiency might similarly translate to performance deficits in ventilation, especially for muscle groups that share postural and pulmonary functions, was the focus of this investigation.

The coordination of skeletal and chest wall muscles during breathing is essential for promoting efficient respiratory function. This balance is especially important in those who are tetraplegic for whom paralysis of sublesional respiratory muscles challenges the paralysis-spared primary and accessory musculature to play a greater role in maintaining adequate ventilation. By definition, accessory respiratory muscles include those attached to the rib cage, shoulder girdle, or vertebral column which assist with inspiration during elevated respiratory demand, but not during quiet ventilation..$^{31,32}$ The sternocleidomastoid and trapezius muscles fully satisfy these criteria, ${ }^{31-33}$ and the scalenes are also classified by several reports as primary muscles of ventilation. ${ }^{33,34}$ This view is supported by subdermal needle EMG analysis showing recruitment of the scalenes during quiet ventilation. ${ }^{29}$

The observation that habitual head posture alone does not influence pulmonary function is consistent with known chronic adaptation of skeletal muscles to changes in their length. ${ }^{35}$ These muscles accommodate to chronic shortening and lengthening by adjusting their structure and function, and in some though not all cases, recover their original length-tension properties. For example, immobilized lengthening of a muscle results in increased weight reflecting changes in its protein content. ${ }^{36,37}$ Some investigators have noted increased peak tension of chronically lengthened muscles ${ }^{38}$ although the magnitude of active peak tension at its original resting length is diminished - a phenomenon referred to as 'stretch weakness'. ${ }^{39}$ Similarly, chronic positioning of a muscle in a shortened position results in loss of sarcomeres, and reduction of passive and active tension..$^{40,41}$ One study suggests that recovery of peak isometric tension occurs within 120 days after resumption of 'free' movement in shortened muscles. ${ }^{42}$ Even after resumption of their free movement, however, these muscles display steeper passive tension curves than unshortened muscles, ${ }^{43}$ increased deposition of connective tissue, ${ }^{44}$ and loss of elastic properties. ${ }^{45}$

While the degree to which habitual forward head posture alone contributes to pulmonary limitations in tetraplegics cannot be determined by this study, it is probable that short term adjustments from habitual position exert more pronounced effects on breathing capacity than the accommodated position itself. Interestingly, the change in head posture of as little as $4 \mathrm{~cm}$ resulted in reduction of FVC and MVV of $10.6 \%$ and $14.3 \%$, respectively, in subjects with habitual forward head position. It is likely that this response is attributable to changes in the lengthtension properties of the muscles sharing postural and breathing assignments. Many studies have shown that acute elongation or shortening of skeletal muscle alters its ability to generate peak tension by changing passive and active length-tension relationships. ${ }^{35}$ Such changes as would occur when moving the head from a forward to a non-forward position, would lengthen the sternocleidomastoid and scalene muscles and shorten their antagonist trapezius stabilizers. For persons without pulmonary dysfunction, these subtle changes in length tension relationships of cervical stabilizing muscles might not be consequential, although tetraplegic individuals who rely to a greater 
extent on accessory muscles in assisting the mobilization of their chest wall, might experience more pronounced effects.

\section{Conclusions}

We conclude that a high percentage of those who are tetraplegic display forward head posture. Movement of the head to a non-habitual posture alters their pulmonary function, likely by modifying the lengthtension relationships of cervical muscles that serve dual functions in postural maintenance and respiration. As the metabolic cost of breathing in tetraplegic individuals is already elevated, and as fewer respiratory muscles are available to assume the burden of ventilatory support, changes in breathing should be anticipated following body or head repositioning resulting from surgical placement or removal of spinal instruments, changes in wheelchair seating, pain, or aging.

\section{Acknowledgements}

The authors thank Liat Alon, MSPT, PT, for her technical help, Dr Kathryn Roach for her invaluable assistance in statistical analysis, and Dr Neil Spielholz for his thoughtful critique of the manuscript. This research was supported, in part, by the Miami Project to Cure Paralysis.

\section{References}

1 Stone DJ, Keltz H. The effect of respiratory muscle dysfunction of pulmonary function. Am Rev Resp Dis 1963; 88: 621-629.

2 McMichan JC, Michael L, Westbrook PR. Pulmonary dysfunction following traumatic quadriplegia. J Am Med Assoc 1980; 243(6): $528-531$

3 Loveridge BM, Dubo HL. Breathing patterns in chronic quadriplegia. Arch Phys Med Rehabil 1990; 71: 495-499.

4 McKinley AC, Auchincloss JH, Gilbert R, Nicholas JJ. Pulmonary function ventilatory control, and respiratory complications in quadriplegic subjects. Amer Rev Resp Dis 1969; 100: $526-532$.

5 Ohry A, Molho M, Rozin R. Alterations of pulmonary function in spinal cord injured patients. Paraplegia 1975; 13: $101-108$

6 Chen CF, Lien IN, Wu MC. Respiratory function in patients with spinal cord injuries: Effects of posture. Paraplegia 1990; 28: $81-86$.

7 Forner JV. Lung volumes and mechanics of breathing in tetraplegics. Paraplegia 1980; 18: $258-266$.

8 Fugl-Meyer AR, Grimby G. Ventilatory function in tetraplegic patients. Scand J Rehab Med 1971; 3: 151 - 160

9 Fugl-Meyer AR. Effects of respiratory muscle paralysis in tetraplegic and paraplegic patients. Scand J Rehab Med 1971; 3: $141-150$.

10 Fugl-Meyer AR, Grimby G. Respiratory mechanics in patients with high spinal cord lesion. Scand J Clin Lab Invest 1969; 24 (Suppl. 110): 44.

11 Forner JV, Llombart L, Valledor MC. The flow-volume loop in tetraplegics. Paraplegia 1977; 15: $245-251$.

12 De Troyer A, Heilporn A. Respiratory mechanics in quadriplegia. The respiratory function of the intercostal muscles. Amer Rev Resp Dis 1980; 122: 591-600.

13 Bergofsky EH. Mechanism for respiratory insufficiency after cervical cord injury. Ann Intern Med 1964; 61: 435 - 447.
14 Haas A, Lowman EW, Bergofsky EH. Impairment of respiration after spinal cord injury. Arch Phys Med Rehabil 1965; 46: $399-$ 404.

15 Hemingway A, Bors E, Hobby RP. An investigation of the pulmonary function of paraplegics. J Clin Invest 1958; 37: 773 782.

16 Moulton A, Silver JR. Chest movements in patients with traumatic injuries of the cervical cord. Clin Sci 1970; 39: 407422.

17 Detroyer A, Estenne M, Heilporn A. Mechanism of active expiration in tetraplegic subjects. $N$ Eng J Med 1986; 314: $740-$ 744.

18 De Troyer A, Deisser P. The effects of intermittent positive breathing on patients with respiratory muscle weakness. Amer Rev Resp Dis 1981; 124: 132-137.

19 Morgan MDL, Silver JR, Williams SJ. The Respiratory System of the Spinal Cord Injured Patient. In: Bloch RF, Basbaum M, editors. Management of Spinal Cord Injuries. Williams \& Wilkins, Baltimore MD: pp. $78-116,1986$.

20 Raper AJ, Thompson WT, Shapiro W. Scalene and sternomastoid muscle function. J Appl Physiol 1966; 21: 497-502.

21 De Troyer A, Estenne M, Vincken W. Rib cage motion and muscle use in high tetraplegics. Am Rev Resp Dis 1986; 133: $1115-1119$.

22 Mannheimer JS, Rosenthal RM. Acute and chronic postural abnormalities as related to craniofacial pain and temporomandibular disorders. Dental Clin N Amer 1991; 35(1): 185-208.

23 Kendall FP, McCreary KE. Muscle Testing and Function. Williams \& Wilkins, Baltimore, MD: p.301, 1983.

24 Rocabado M. Biomechanical relationship of the cranial, cervical, and hyoid regions. J Craniomandibular Prac 1983; 1(3): 61-66.

25 Mortola JP, Sant'Ambrogio G. Mechanics of breathing in tetraplegics. Am Rev Resp Dis 1979; 119: 131-134.

26 Mortola JP, Sant'Ambrogio G. Motion of the rib cage and the abdomen in tetraplegic patients. Clin Sci Mol Med 1978; 54: 25 32.

27 Tichauer ER. Industrial engineering in the rehabilitation of the handicapped. J Industr Eng 1968; 19: $94-104$.

28 Mayoux-Benhamou MA, Revel M. Influence of head position on dorsal neck muscle efficiency. Electromyogr Clin Neurophysiol 1993; 33: $161-166$

29 Keshner EA, Campbell D, Katz RT, Peterson BW. Neck muscle activation patterns in humans during isometric head stabilization. Exp Brain Res 1989; 75: 335-344.

30 Caffin DB. Localized muscle fatigue. Definition and measurement. J Occup Med 1973; 15: 346-354.

31 Celli BR. Clinical and physiologic evaluation of respiratory muscle function. Clin Chest Med 1989; 10: 199-214.

32 Crane LD. Functional anatomy and physiology of ventilation. Pulmonary Management in Physical Therapy. Churchill Livingstone: pp. 1-21, 1992.

33 Raper AJ, Thompson WT Jr., Shapiro W, Patterson JL Jr. Scalene and sternomastoid muscle function. J Appl Physiol 1966; 21(2): $497-502$

34 Thompson WT Jr., Patterson JL Jr., Shapiro W. Observations on the scalene respiratory muscles. Arch Int Med 1964; 113: 856865.

35 Gossman MR, Sahrmann SA, Rose SJ. Review of lengthassociated changes in muscle: experimental evidence and clinical implications. Phys Ther 1982; 62(10): 1798-1807.

36 Tabary JC, Tabary C, Tardieu C, Tardieu G, Goldspink G Physiological and structural changes in the cat's soleus muscle due to immobilization at different lengths by plaster casts. $J$ Physiol (Lond) 1972; 224: $231-244$.

37 Crawford GNC. The growth of striated muscle immobilized in extension. J Anat 1973; 114: $165-183$.

38 Williams PE, Goldspink G. Changes in sarcomere length and physiological properties in immobilized muscle. J Anat 1978; 127: $459-468$

39 Kendall HO, Kendall FP, Wadsworth GE: Muscles, Testing and Function, ed 2. Baltimore, MI), The Williams \& Wilkins Co, pp $3-15,1979$. 
40 Goldspink DF. The influence of activity on muscle size and protein turnover. J Physiol (Lond) 1977; 264: 283-296.

41 Goldspink DF. The influence of immobilization and stretch on protein turnover of rat skeletal muscle. J Physiol (Lond) 1977; 264: $267-282$.

42 Booth FW, Seider MJ. Recovery of skeletal muscle after three months of hindlimb immobilization in rats. J Appl Physiol 1979; 47: $435-439$.
43 Williams PE, Goldspink G. The effect of immobilization on the longitudinal growth of striated muscle fibers. J Anat 1973; 116: $45-55$.

44 Goldspink G. The adaptation of muscle to new functional length. In: Anderson DJ, Mathews B, ed. Mastication. Bristol, England, Wright, pp. $90-99,1976$. 